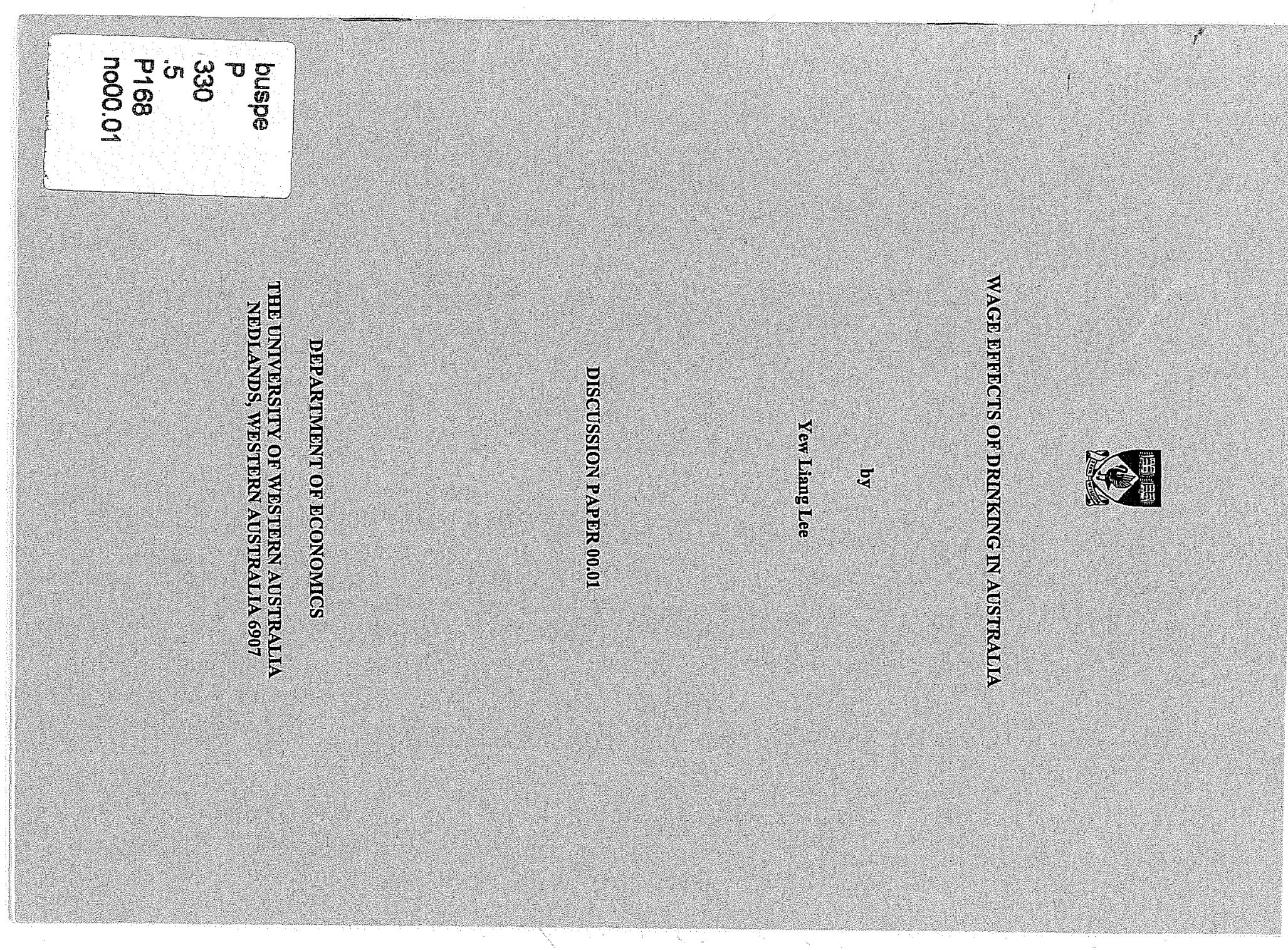


Yew Liang Lee

Department of Economics

The University of Western Australia

DISCUSSION PAPER 00.01

DEPARTMENT OF ECONOMICS

THE UNIVERSITY OF WESTERN AUSTRALIA NEDLANDS, WESTERN AUSTRALIA 6907

* The anthor would like to express his sincere gratitude to Nick Martin (Queensland Institute of 


\section{WAGE EFFECTS OF DRINKING IN AUSTRALIA}

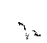

\section{ABSTRACT}

This paper analyses the wage effects of drinking using the Australian Twin Registry data. A multinomial logit framework is employed to explain the allocation of workers across various drinking states, and to correct for selection bias in the estimating equation. It is found that there are significant positive wage premiums for both light and moderate drinking. The quite substantial positive effect of moderate drinking, in the Australian twins sample, is hidden in the raw wage differential by negative sample selection into this drinking category.

\section{Introduction}

The main objective of this research is to separate the wage effects of observed and unobserved personal characteristics that may be correlated with both drinking status and labour market outcomes. The effects of drinking on wages have been the focus of a number of recent studies, including Berger and Leigh (1988), Mullahy and Sindelar (1993), Kenkel and Ribar (1994), French and Zarkin (1995), Heien (1996), Hamilton and Hamilton (1997) and Zarkin et al. (1998). It is argued that alcohol consumption can have both short-run and long-run effects on productivity and wages. Much of the discussion is in terms of alcohol consumption being linked to lower wages. For example, short-run drinking problems have been linked to workplace behaviours (e.g., taking long lunch breaks, high absenteeism) that lower productivity. In the long run, drinking problems may reduce productivity and wages through affecting the worker's health capital, schooling capital, and labour market experience. At the same time it has been noted that some types of drinking behaviour may actually be associated with relatively higher wages. French and Zarkin (1995) report that a significant wage premium exists for drinkers who do not drink excessively. Zarkin et al. (1998) find that, after controlling for observable characteristics, drinkers have around a 7 percent wage advantage over non-drinkers. Hence, whether alcohol consumption is associated with higher or lower wages is largely an empirical matter.

Knowledge of the wage effects of drinking is important because it allows cost-benefit analyses of this form of addictive behaviour to be conducted. In terms of benefits, drinking provides a relaxing sensation and enhances acceptance by their peers for 
some people. Turner et al. (1981) point out that moderate alcohol consumption leads to a lower risk of coronary heart disease relative to abstainers.

$$
\text { r. }
$$

The costs of drinking can be categorised into both private and social costs. The private costs of drinking are incurred by the drinkers themselves. They include the cost of buying alcohol, the cost of private medical treatment for drinking-related sickness, and any lower wages associated with reductions in productivity among drinkers. On the other hand, other social costs of drinking are incurred by nondrinkers who bear the cost of subsidising medical treatment through public health systems. One of the main social costs of alcohol abuse is the cost associated with car accidents.

Thus, it is apparent that any evaluation of the net costs of aicohol consumption will require information on the wage effects of this form of addictive behaviour. These wage effects must be determined after making allowance for other influences on wages. In this regard, the recent work by Hamilton and Hamilton (1997) provides the most comprehensive approach of the various studies noted above. They examined the impact of alcohol consumption on earnings within the context of the sample selection model developed by Heckman (1979) and Lee (1983). This model allows the wage effects of drinking on earnings to be analysed after making allowance for the possibility that individuals self-select into (i.e., choose to be in) the various drinking states identified in the analysis.

The aim of this paper is to study the wage effects of drinking in the Australian labour market using the sample selection model proposed by Hamilton and Hamilton (1997).
This will provide the opportunity for a multivariate analysis of the determinants of drinking, which will be a novel application of choice-based modelling in the Australian literature. The analyses will be based on data from the Australian Twin Registry, a data source that has considerable potential for labour market analyses. It is noted that the focus of this paper is on a detailed study of the wage effects of drinking behaviour. While the twin data set is used, the twins dimension of this is not emphasised. This is due to the fact that the sample size in a number of the applications would be too small to permit reliable estimates of the wage effects of drinking to be obtained using samples disaggregated by twin type as well as by drinking category.

The structure of this paper is as follows. Section II provides a description of the Australian Twin Registry data, and of how the various drinking states are constructed. In section III, a multinomial logit model to explain the allocation of workers across the various drinking states is outlined, and estimates from the model are presented. Section IV, which discusses the wage model, is divided into a few sub-sections. The first of these briefly outlines the wage model. OLS estimates of this model are reported in the second sub-section. The third sub-section presents selectivity-corrected estimates. Analyses of a decomposition of wage differentials among drinkers are then provided. A summary and conclusion are contained in section $\mathrm{V}$.

\section{The Data and Sample}

The data analysed in this study are from the Australian Twin Registry which were gathered in two surveys, in 1980-1982 and 1988-1989. In 1980-1982, a mail-out 
survey was conducted of all 5967 adult twin pairs throughout Australia aged over 18 years who were enrolled in the Australian National Health and Medical Research Council Twin Registry during that period. Being enrolled in this registry and taking part in the survey were both voluntary. The response rate was about 64 percent, with replies being received from 3808 complete pairs of twins after one or two reminders to non-respondents.

The sample of 3808 complete twin pairs was followed up in 1988-1989, and responses were obtained from 6327 individuals, which includes 2995 complete pairs of twins.

The data utilised in this study are mostly from the follow-up survey. Information on the respondent's family background, socioeconomic status and personal details was recorded. Data on the respondent's family background include extensive information on the respondent's parents, siblings, and marital status. Education level, employment status, income level, and occupation form the major measures of socioeconomic status. The information on personal details collected was more detailed than is usual in large-scale surveys and included questions about drinking and smoking habits.

As pointed out in Miller et al. (1995), the respondents to the survey have, on average, about one year of schooling more than the national average recorded in the 1986 Australian Census of Population and Housing. Furthermore, the respondents are, on average, one year younger than the population of 20-64 year olds. It is generally found that samples of twins have these features compared to national data (see, for example, Ashenfelter and Krueger (1994)).
It is crucial to note that some of the information used in this study was gathered in categorical form. The data on education were collected in seven categories.' Also collected in categorical form are the data on income, with only eight categories being used. ${ }^{2}$ These categorical income data have been converted to a continuous measure by choosing the midpoints of each category. For example, for the category $\$ 5000$ $\$ 10000$, the value $\$ 7500$ was chosen to represent the individual measure for that category. A value of $\$ 75000$ was used for the open-ended upper category of $\$ 50000$.

Of the 2995 pairs of twins who responded to the 1988-1989 survey, there were 923 pairs of twins for whom complete information was available. As a consequence, this analysis is based on a total of 1846 individuals.

To allow a more detailed ascertainment of the wage effects of drinking, the approach of Hamilton and Hamilton (1997) is adopted to separate drinkers into non-, light, moderate and heavy drinkers by both the frequency and intensity of drinking. The information collected about drinking in the Australian twin survey allows drinking variables to be constructed that are broadly in line with those proposed by Hamilton

\footnotetext{
The seven categories are: $<7$ years of schooling; $11-12$ years of schooling; apprenticeship, diploma, certificate; technical or teachers college; university, first degree; university, postgraduate degree. The present analysis uses education variables that were recoded as $5,9,11.5,11.5,13,15$ and 17 years of education, respectively. Miller et al. (1995) point out that the recoding of the education variables affects a number of individual findings, such as reliability ratios. However, the general gist of the conclusions derived from the study is not severely affected by reasonable variations in the assumed mean levels of education for each category.

${ }^{2}$ In the survey, respondents were asked: "Thinking of the income your family makes from all sources salaries, investments, pensions, and other sources - approximately how much did you earn before tax (gross) during 1987-1988?" Eight response categories were provided. The categories are: none; under $\$ 5000 ; \$ 5000-\$ 10000 ; \$ 10000-\$ 15000 ; \$ 15000-\$ 25000 ; \$ 25000-\$ 35000 ; \$ 35000-\$ 50$ 000; over $\$ 50000$.
} 
and Hamilton (1997). ${ }^{3}$ Non-drinkers are defined as those who did not drink at all in the past 12 months or do not drink at all in a typical week. Light drinkers consumed alcoholic dirinks once or twice a month or less often during the past 12 months and consume between 1 and 12 drinks, on average, in a week. Those who drank 3-4 times a week or once or twice a week during the past 12 months and have between 13 and 24 drinks in a typical week are classified as moderate drinkers. Heavy drinkers are defined as those who drank more than once a day or every day during the past 12 months and have at least 25 drinks a week. However, there were too few individuals (41) classified as such to be able to derive meaningful estimates. The few respondents who met the criteria for heavy drinking are included in the moderate drinker category.

Table 1: Summary of Various Drinking Categories - Australian Twin Survey

\begin{tabular}{|c|c|c|}
\hline Category & Incidence of Drinking & Average Quantities Consumed \\
\hline Light & $\begin{array}{l}<1-2 \text { times per month } \\
\quad \text { or } \\
1-2 \text { times per month }\end{array}$ & 1-12 drinks per week \\
\hline Moderate & $\begin{array}{l}\text { 1-2 times per week } \\
\text { or } \\
\text { 3-4 times per week }\end{array}$ & 13-24 drinks per week \\
\hline Heavy & $\begin{array}{c}\text { Every day } \\
\text { or } \\
\text { More than once a week }\end{array}$ & $>25$ drinks per week \\
\hline
\end{tabular}

${ }^{3}$ Hamilton and Hamilton (1997) define non-drinkers as those who drank less than once a month or not at all over the past 12 months. They define moderate drinkers as those who drank once or twice a month, once a week or every day, but never consumed 8 or more drinks during a single day in the past consuming 8 or more drinks on one or more days in the previous week.
A summary of the various drinking categories is provided in Table 1. There are 365 non-drinkers, 340 light drinkers and 1141 moderate drinkers in this sample. ${ }^{4}$

Descriptive statistics for the key variables employed in the analysis are presented in Table 2. Computations of the statistics are made for the respondents, aged 20-64 years, who provide information on each of the variables used in the analysis. Columns (i), (ii) and (iii) list the means of each variable for non-, light and moderate drinkers, respectively.

Table 2: Descriptive Statistics for Non-Drinkers, Light Drinkers and Moderate Drinkers Australian Twin Survey

\begin{tabular}{lccc}
\hline & \multicolumn{3}{c}{ Means (standard deviations in parentheses) } \\
Variable & $\begin{array}{c}\text { Non-Drinkers } \\
\text { (i) }\end{array}$ & $\begin{array}{c}\text { Light Drinkers } \\
\text { (ii) }\end{array}$ & $\begin{array}{c}\text { Moderate Drinkers } \\
\text { (iii) }\end{array}$ \\
\hline Self-reported education (years) & 12.436 & 12.866 & 13.022 \\
& $(2.42)$ & $(2.35)$ & $(2.44)$ \\
Age (years) & 35.274 & 35.235 & 35.543 \\
& $(7.88)$ & $(8.18)$ & $(7.98)$ \\
Married (proportion) & 0.704 & 0.744 & 0.740 \\
& $(0.46)$ & $(0.44)$ & $(0.44)$ \\
Male (proportion) & 0.389 & 0.444 & 0.552 \\
& $(0.49)$ & $(0.50)$ & $(0.50)$ \\
Employment-Full-time & 0.740 & 0.762 & 0.859 \\
(proportion) & $(0.44)$ & $(0.43)$ & $(0.35)$ \\
Log of annual income & 9.832 & 10.005 & 10.165 \\
& $(0.79)$ & $(0.70)$ & $(0.65)$ \\
Sample size & 365 & 340 & 1141 \\
& & & \\
\hline
\end{tabular}

${ }^{4}$ Hamilton and Hamilton's (1997) sample includes 313 non-drinkers, 1256 moderate drinkers and 172 heavy drinkers. 
The mean self-reported level of education is the highest in the moderate drinking category. As suggested by Table 2, the proportion of married individuals and the proportion of male individuals are the smallest in the non-drinking group. The largest proportion of full-time employed workers is in the moderate drinking group. Moderate drinkers have the highest mean (logarithmic) annual income.

\section{The Determinants of Drinking Behaviour}

\section{Multinomial Logit Model}

The drinking variable has discrete, mutually exclusive outcomes. ${ }^{5}$ When these representations of drinking are to be a dependent variable, conventional regression models (such as ordinary least squares (OLS)) are not appropriate. A multinomial logit model can, however, be used in such a study. In the multinomial logit framework, the dependent drinking variable is categorised into various states. The model then allows an assessment of whether particular background variables (e.g., individual characteristics, family background) affect membership of these various drinking states. Estimates obtained from such a model are subsequently used to explore the possibility of non-random selection into the various drinking states.

\section{Consider the model}

$$
D_{i}=\alpha+\beta^{\prime} X_{i}+u_{i}
$$

\footnotetext{
${ }_{5}^{5}$ The various drinking states used in this study are discussed in section II.
}

where $u_{i} \sim \mathrm{N}(0,1)$ and $D$ is an unobservable variable which indexes drinking behaviours. $D$ can be interpreted as the underlying tendency to drink, which is not observed. Instead, discrete data on drinking type are observed. They are in the form of the variable $D_{i}=1,2, \ldots, k$ where there are $k$ drinking categories. ${ }^{6} X$ is a $n \times 1$ vector of explanatory (or exogenous) variables.

With the multinomial logit specification, the conditional probability that individual $i$ is in drinking $h$ may be expressed as

$$
P_{i h} \mid X_{i}=\frac{e^{\beta_{h}^{\prime} X_{i}}}{\sum_{j=1}^{k} e^{\beta_{j}^{\prime} X_{i}}}
$$

There are $k$ drinking categories. Since each individual must select one drinking status, only $k-1$ sets of coefficients are uniquely defined. ${ }^{7}$ Normalising by setting the first set of coefficients to zero (i.e., $\beta_{1}=0$ ), the log odds ratio can be written as

$$
\ln \left[\frac{P_{i h}}{p_{i 1}}\right]=\ln \left[\frac{e^{\beta_{i}^{i} X_{i}}}{e^{\beta_{i} X_{i}}}\right]=\beta_{h} X_{i}
$$

where $\beta_{h}$ provides a measure of the impact of the explanatory variables $X$ on the log odds of being in drinking category $h$ as opposed to the non-drinking category.

${ }^{6}$ With three drinking categories (namely, non-, light and moderate) defined in this analysis, $D_{i}=1,2$, and 3 where the individual is a non-drinker, the individual is a light drinker and the individual is a moderate drinker, respectively

${ }^{7}$ In this analysis, only $2(=3-1)$ sets of coefficients are uniquely defined. 
Using non-drinkers as the base category, the results provided in column (i) of Table 3 indicate how each variable affects the log odds ratio of an individual being a light drinker relative to a non-drinker. Only two variables are statistically significant. The positive coefficient on the marital status variable indicates that marriage has a positive impact on the log odds of being a light drinker. Increasing age, on the other hand, has a negative impact on the log odds of being a light drinker. The insignificance of the remaining regressors suggests there are few observed indicators that can be used to distinguish light drinkers from non-drinkers.

Column (ii) of Table 3 presents results that show how the $\log$ odds ratio of an individual being a moderate drinker (relative to a non-drinker) is affected by each variable. In this comparison, five regressors are statistically significant. Individuals who are male, married and employed on a full-time basis have a higher probability of being a moderate drinker relative to being a non-drinker. Mother's education has a positive impact on the odds ratio of being a moderate drinker. On the other hand, increasing age has a negative impact on the odds ratio of being a moderate drinker.

The greater number of statistically significant regressors in column (ii) compared to column (i) shows that membership of drinking categories that are more distant apart can be accounted for more readily than membership of drinking categories that are closer together.

The variables included in the model of drinking behaviours in general influence

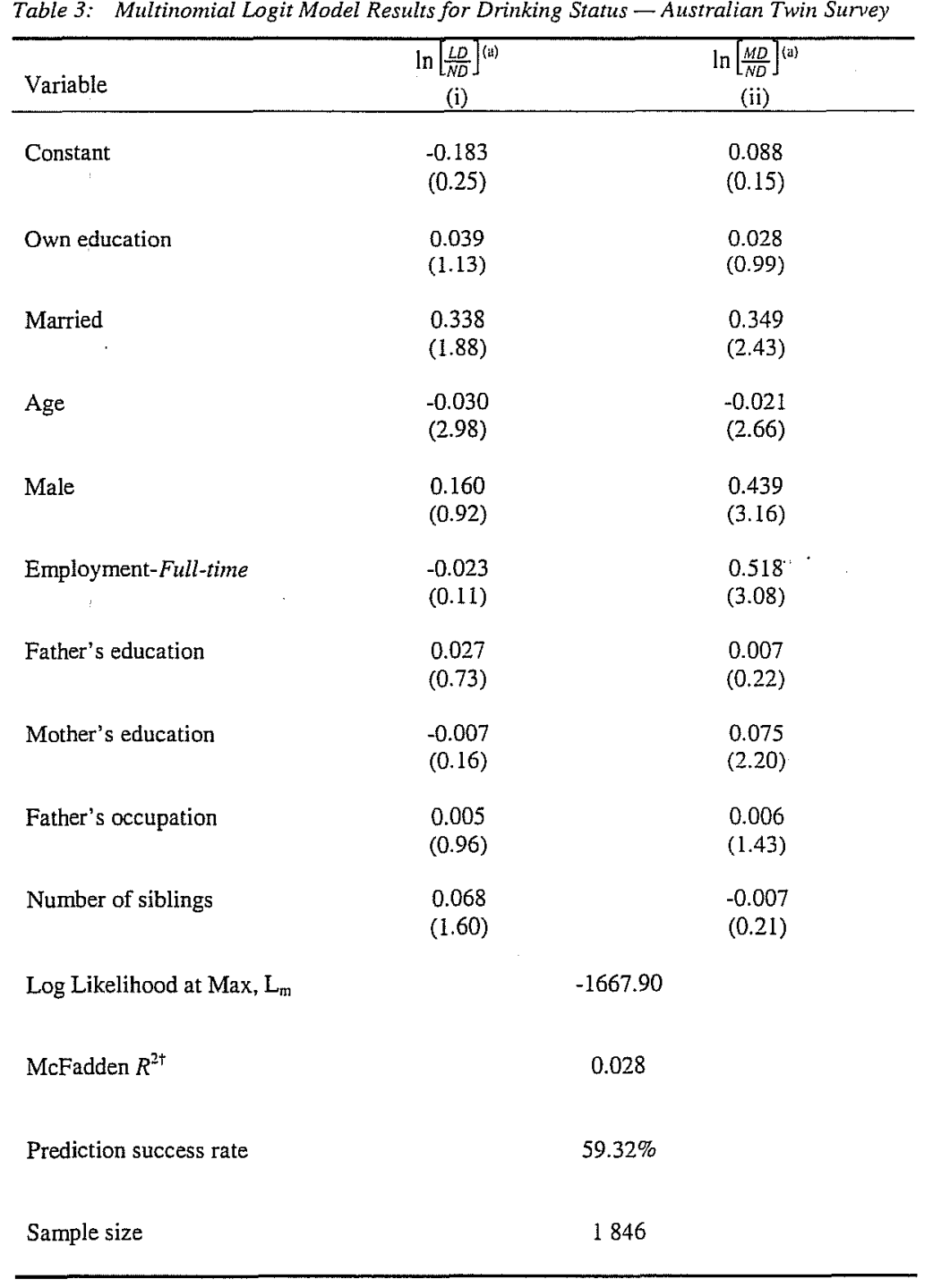

Notes: Numbers in parentheses are $t$ statistics.

(i) $L D, M D$ and $N D$ denote light drinkers, moderate drinkers and non-drinkers, respectively. + The McFadden $R^{2}$ is calculated as $1-\left(I_{\mathrm{m}} L_{0}\right)$, where $L_{\mathrm{m}}=$ the log-likelihood value of the model and $L_{0}=$ the log-likelihood value if the non-intercept coefficients are restricted to zero (see Veall and Zimmermann (1996)) 
drinking in the direction one would expect. They, therefore, provide a sound basis on which to form selection correction terms for the wage equation estimates to be discussed int the next section.

\section{Study of Wages}

\section{Introduction}

To analyse the determinants of earnings for various categories (non-, light and moderate), two approaches are employed. The first of these is conventional OLS estimation. The second approach used is selectivity-corrected estimation. This latter approach allows the exploration of possible non-random selection into the various drinking states.

\section{OLS Results}

Table 4 presents OLS estimates of log annual earnings for non-drinkers, light drinkers and moderate drinkers in the first three columns, and for the total sample pooled across drinking states in column (iv). The explanatory powers of the wage regressions for the three different states are quite high, as the $\bar{R}^{2}$ values range between 0.38 (light drinkers) and 0.46 (non-drinkers). An examination of the estimates reveals that the patterns of the results, in terms of statistical significance and size of the estimated coefficients, are uniform across the table.

The estimated returns to schooling range from 6.1 percent (light drinkers) to 7.0
Table 4: Ordinary Least Squares (OLS) Estimates of Log Annual Earnings for Non Drinkers, Light Drinkers and Moderate Drinkers Using Individual Income Data - Australian Twin Survey

\begin{tabular}{|c|c|c|c|c|}
\hline Variable & $\begin{array}{l}\text { Non-Drinkers } \\
\text { (i) }\end{array}$ & $\begin{array}{l}\text { Light Drinkers } \\
\text { (ii) }\end{array}$ & $\begin{array}{l}\begin{array}{l}\text { Moderate Drinkers } \\
\text { (iii) }\end{array} \\
\end{array}$ & $\begin{array}{l}\text { Total sample } \\
\text { (iv) }\end{array}$ \\
\hline Constant & $\begin{array}{l}8.078 \\
(30.96)\end{array}$ & $\begin{array}{c}8.443 \\
(32.26)\end{array}$ & $\begin{array}{c}8.310 \\
(61.40)\end{array}$ & $\begin{array}{c}8.197 \\
(74.87)\end{array}$ \\
\hline Own education & $\begin{array}{l}0.070 \\
(6.46)\end{array}$ & $\begin{array}{l}0.061 \\
(4.76)\end{array}$ & $\begin{array}{c}0.066 \\
(10.72)\end{array}$ & $\begin{array}{c}0.061 \\
(11.37)\end{array}$ \\
\hline Married & $\begin{array}{l}-0.054 \\
(0.85)\end{array}$ & $\begin{array}{l}0.032 \\
(0.52)\end{array}$ & $\begin{array}{l}0.050 \\
(1.55)\end{array}$ & $\begin{array}{l}0.002 \\
(0.08)\end{array}$ \\
\hline Age & $\begin{array}{l}0.014 \\
(3.42)\end{array}$ & $\begin{array}{l}0.011 \\
(3.02)\end{array}$ & $\begin{array}{l}0.010 \\
(4.87)\end{array}$ & $\begin{array}{l}0.011 \\
(7.02)\end{array}$ \\
\hline Male & $\begin{array}{l}0.330 \\
(5.13)\end{array}$ & $\begin{array}{l}0.307 \\
(5.46)\end{array}$ & $\begin{array}{l}0.273 \\
(9.43)\end{array}$ & $\begin{array}{c}0.289 \\
(10.21)\end{array}$ \\
\hline $\begin{array}{l}\text { Employment - } \\
\text { Full-time }\end{array}$ & $\begin{array}{l}0.829 \\
(9.51)\end{array}$ & $\begin{array}{l}0.707 \\
(6.81)\end{array}$ & $\begin{array}{c}0.860 \\
(13.45)\end{array}$ & $\begin{array}{c}0.875 \\
(24.21)\end{array}$ \\
\hline $\begin{array}{l}\text { Drinking - } \\
\text { Light }\end{array}$ & $-^{(a)}$ & $-^{(\mathrm{a})}$ & $-^{(\mathrm{a})}$ & $\begin{array}{l}0.124 \\
(2.85)\end{array}$ \\
\hline $\begin{array}{l}\text { Drinking - } \\
\text { Moderate }\end{array}$ & $-^{(\mathrm{a})}$ & $-^{\text {(a) }}$ & $-(w)$ & $\begin{array}{l}0.143 \\
(4.72)\end{array}$ \\
\hline$R^{2}$ & 0.468 & 0.388 & 0.434 & 0.464 \\
\hline $\bar{R}^{2}$ & 0.461 & 0.379 & 0.421 & 0.462 \\
\hline Sample size & 365 & 340 & 1141 & 1846 \\
\hline
\end{tabular}

Note: Numbers in parentheses are $t$ statistics.

percent (non-drinkers). The effects age has on earnings are between 1 percent (moderate drinkers) and 1.4 percent (non-drinkers). Male individuals have between 
27.3 percent (moderate drinkers) and 33 percent (non-drinkers) higher earnings than their female counterparts in the respective drinking categories. For each of the drinker types, individuals who work full-time earn more than those who are employed on a part-time basis. The values range from 102.79 percent (light drinkers) to 136.32 percent (moderate drinkers). ${ }^{8}$

When dummy variables for light and moderate drinkers are included in the estimating equation for the entire sample (see column (iv) of Table 4), the OLS estimates indicate that light and moderate drinkers earn 12.4 percent and 14.3 percent more than non-drinkers, respectively. ${ }^{9}$ The coefficients on the other variables are quite similar to those reported for the various drinking categories (compare with columns (i), (ii) and (iii)).

\section{Selectivity-Corrected Results}

To control for selectivity bias, selectivity variables ( $\lambda$ 's) are modelled for inclusion in the earnings equations for non-drinkers, light drinkers and moderate drinkers. These variables account for self-selection bias which may arise when individuals choose a particular drinking status (see Lee (1983)). In this analysis, all the $\lambda^{\prime}$ 's have been constructed to be positive. A positive coefficient on the selectivity variable will

\footnotetext{
${ }^{8}$ These values are computed using the equation formulated by Halvorsen and Palmquist (1980). The algorithm should be used where estimated coefficients are large. Where estimated coefficients on dummy variables are of moderate size, they can be interpreted as percentage point impacts.

9 These results are consistent with most of the literature. Berger and Leigh (1988) find that male drinkers earn 36.2 percent more than male non-drinkers, and female drinkers have a 28.7 percen income advantage over female non-drinkers. Hamilton and Hamilton (1997) report that moderate drinkers ( 72 percent of the sample) earn 7 percent more than non-drinkers ( 18 percent of the sample) while heavy drinkers (10 percent of the sample) earn 14 percent more than non-drinkers.
}

therefore indicate positive selection into the drinking category, while a negative coefficient will be associated with negative selection into the drinking category. ${ }^{10}$

Results for the selection corrected wage regressions for drinking are presented in Table 5. For both non-drinking and moderate drinking groups, the inclusion of selectivity variables ( $\lambda$ 's) increases the $\bar{R}^{2}$ values. For all three drinking states, the estimated coefficients on schooling are positive and statistically significant. They range in value from 4.7 percent (non-drinkers) to 6.0 percent (light drinkers). The results on the age variable are identical for both light and moderate drinkers, but that for non-drinkers is almost twice the magnitude reported for the other drinking categories. The gender wage effects are positive for all the drinking states. Full-time employed individuals earn between 99.37 percent (non-drinkers) and 109.17 percent (light drinkers) more than individuals who work part time.

The impacts of the selectivity correction variables on the earnings of non-drinkers, light drinkers and moderate drinkers are also presented in Table 5. For non-drinkers, the positive and significant coefficient on the selectivity variable indicates positive selection into the non-drinking category (see column (i)). In other words, the unobserved characteristics that lead to an above average probability of selection into non-drinking lead to above average earnings in that drinking category. For moderate drinkers, the coefficient of the selectivity variable is negative (see column (iii) of Table 5). The negative selection means that those whose unobservables are relatively

\footnotetext{
${ }^{10}$ See Dolton and Makepeace (1987) for interpretations of selectivity variables.
} 
Table 5: Selectivity-Gorrected Estimates of Log Annual Eamings for Non-Drinkers, Light Drinkers and Moderate Drinkers Using Individual Income Data - Australian Twin Survey

\begin{tabular}{|c|c|c|c|}
\hline Variable & $\begin{array}{l}\text { Non-Drinkers } \\
\text { (i) }\end{array}$ & $\begin{array}{l}\text { Light Drinkers } \\
\text { (ii) }\end{array}$ & $\begin{array}{l}\text { Moderate Drinkers } \\
\text { (iii) }\end{array}$ \\
\hline Constant & $\begin{array}{c}6.948 \\
(13.43)\end{array}$ & $\begin{array}{c}8.679 \\
(17.09)\end{array}$ & $\begin{array}{c}8.910 \\
(39.24)\end{array}$ \\
\hline Own education & $\begin{array}{l}0.047 \\
(2.91)\end{array}$ & $\begin{array}{l}0.060 \\
(4.55)\end{array}$ & $\begin{array}{l}0.057 \\
(8.06)\end{array}$ \\
\hline Married & $\begin{array}{l}-0.191 \\
(2.15)\end{array}$ & $\begin{array}{l}0.029 \\
(0.41)\end{array}$ & $\begin{array}{l}0.004 \\
(0.11)\end{array}$ \\
\hline Age & $\begin{array}{l}0.023 \\
(4.26)\end{array}$ & $\begin{array}{l}0.012 \\
(2.74)\end{array}$ & $\begin{array}{l}0.012 \\
(5.63)\end{array}$ \\
\hline Male & $\begin{array}{l}0.177 \\
(1.91)\end{array}$ & $\begin{array}{l}0.325 \\
(4.30)\end{array}$ & $\begin{array}{l}0.189 \\
(4.44)\end{array}$ \\
\hline Employment-Full-time & $\begin{array}{l}0.690 \\
(7.06)\end{array}$ & $\begin{array}{l}0.738 \\
(7.47)\end{array}$ & $\begin{array}{c}0.718 \\
(11.39)\end{array}$ \\
\hline Selectivity variable, $\lambda$ & $\begin{array}{l}0.868 \\
(2.54)\end{array}$ & $\begin{array}{l}-0.197 \\
(0.54)\end{array}$ & $\begin{array}{l}-0.743 \\
(3.27)\end{array}$ \\
\hline$R^{2}$ & 0.478 & 0.389 & 0.430 \\
\hline $\bar{R}^{2}$ & 0.469 & 0.378 & 0.427 \\
\hline Sample size & 365 & 340 & 1141 \\
\hline
\end{tabular}

Note: Numbers in parentheses are $t$ statistics.

poorly rewarded in the moderate drinking category are more likely to be in that category. For example, consider an unobserved characteristic such as a "more sociable" person. This characteristic might result in the person having an above average probability of being a moderate drinker, but because he/she socialises rather than works hard in the workplace, he/she has a below average wage.
4. Wage Decomposition Analysis

In order to distinguish the contribution of various factors to differences in income returns across drinker types, a wage decomposition (see Blinder (1973), Oaxaca (1973)) is employed. Adopting the technique of Idson and Feaster (1990), the mean wage difference between any two groups of drinkers, $j$ and $k$, may be decomposed as

$$
\bar{W}_{j}-\bar{W}_{k}=0.5\left(\hat{\beta}_{j}+\hat{\beta}_{k}\right)^{\prime}\left(\bar{X}_{j}-\bar{X}_{k}\right)+0.5\left(\hat{\beta}_{j}-\hat{\beta}_{k}\right)^{\prime}\left(\bar{X}_{j}+\bar{X}_{k}\right)+\left(\bar{u}_{j}-\bar{u}_{k}\right)
$$

where a bar over a variable indicates the mean level and $\hat{\beta}$ refers to the estimated value of the parameter.

The first term on the right-hand side, $0.5\left(\hat{\beta}_{j}+\hat{\beta}_{k}\right)\left(\bar{X}_{j}-\bar{X}_{k}\right)$, represents that part of the wage differential attributable to differences in characteristics across drinking categories. The second term $0.5\left(\hat{\beta}_{j}-\hat{\beta}_{k}\right)^{\prime}\left(\bar{X}_{j}+\bar{X}_{k}\right)$ measures the part of the wage differential between categories due to differences in returns to these characteristics. Hamilton and Hamilton (1997) refer to this term as a pure wage differential, as it measures differences in the productivity of status $j$ versus status $k$ drinkers with the same observed characteristics. The final term $\left(\bar{u}_{j}-\bar{u}_{k}\right)$ denotes the mean difference in residuals across two given drinking categories resulting from the sample selection bias.

The decomposition of the wage differentials between the various drinking states are presented in Table 6 . Row (A) of Table 6 presents the wage differential between light 
drinkers and non-drinkers. The figure in column (i) indicates that light drinkers earn, on average, around 17 percent more than non-drinkers. The small figure of 0.013 in the second column is the measure of the part of the mean wage differential that is attributable to the different.observed characteristics of the two groups of drinkers. The small value indicates that the two groups have similar mean values of the observable indicators of productivity. The data in column (iii) show the impact on earnings of different treatments in the labour market of the two drinking groups under consideration. The large positive value indicates that, other things the same, light drinkers have higher mean earnings than non-drinkers because their observed characteristics (e.g., schooling, gender, full-time employment) attract relatively high rates of pay.

The final column of Table 6 shows how self-selection into the drinking states impacts on earnings. The negative wage effect of -1.459 indicates that the negative selfselection into the light-drinking category (on the basis of unobservables) and the positive selection of non-drinkers serves to depress the earnings of light-drinkers relative to non-drinkers.

Table 6: Decomposition of Wage Differentials for Drinkers - Australian Twin Survey

\begin{tabular}{llccr}
\hline & (i) & (ii) & (iii) & (iv) \\
\hline & $\bar{W}_{j}-\bar{W}_{k}=0.5\left(\hat{\beta}_{j}+\hat{\beta}_{k}\right)^{\prime}\left(\bar{X}_{j}-\bar{X}_{k}\right)+0.5\left(\hat{\beta}_{j}-\hat{\beta}_{k}\right)^{\prime}\left(\bar{X}_{j}+\bar{X}_{k}\right)+\left(\bar{u}_{j}-\bar{u}_{k}\right)$ \\
(A) $\bar{W}_{L}-\bar{W}_{N}$ & 0.174 & 0.013 & 1.619 & -1.459 \\
(B) $\bar{W}_{M}-\bar{W}_{N}$ & 0.333 & 0.111 & 1.844 & -1.622 \\
\hline
\end{tabular}

Notes: $\bar{W}_{N}, \bar{W}_{L}$ and $\bar{W}_{M}$ denote the mean wages of non-drinkers, light drinkers and moderate drinkers, respectively.
These results show that in order to understand the mean wage differentials between workers in the various drinking states in traditional OLS analysis, account must be taken of the influences of both observed and unobserved factors. The fixed-effects model (not discussed in this paper, but available upon request) provides an alternative way of accounting for some of the influences of the unobserved factors.

Row (B) of Table 6 reports results obtained when decomposing the wage gap between moderate drinkers and non-drinkers. The positive value of 33.3 percent in column (i) of row (B) reflects the higher mean earnings of moderate drinkers relative to nondrinkers in the data. The positive values in columns (ii) and (iii) of row (B) indicate that the higher earnings for moderate drinkers are attributable to both higher mean characteristics and higher returns to these characteristics relative to non-drinkers. The negative effect attributable to sample selection in column (iv) almost offsets the positive pure-wage differential due to moderate drinking in column (iii). Thus, a substantial positive effect of moderate drinking on productivity is hidden in the raw wage differential by negative sample selection into moderate drinking (as found in sub-section 3)

The set of results reported in row (B) of Table 6 are consistent with those of Hamilton and Hamilton (1997). This supports the stance that moderate drinking leads to increased productivity in the workforce, and thus earnings (Zarkin et al. (1998)). As Hamilton and Hamilton (1997) did not conduct any analyses based on light drinking, the other set of results presented in row (A) of Table 6 cannot be compared. 


\section{Summary and Conclusion}

An attempt is made to provide additional information on the wage effects of drinking by constructing detailed yariables to describe drinking behaviours. Hence, drinkers are separated into three mutually exclusive categories: non-, light and moderate/heavy. Analyses of the determinants of earnings are undertaken for various categories (non-, light and moderate) of drinkers. Two approaches are followed, namely conventional OLS estimation and selectivity-corrected estimation. The selectivity-corrected estimation allows the exploration of possible non-random selection into the various drinking states.

Estimates obtained from the multinomial logit framework (where the dependent drinking variable is categorised as non-, light and moderate drinkers) show that the variables included in the models of drinking behaviours in general influence drinking states in the expected direction.

Using the multinomial logit model estimates to form selection corrected terms for the wage equation estimates, the selectivity-corrected results indicate that, for all drinker types, the estimates of the return to schooling range between 4.7 percent and 6.0 percent. There is positive selection into non-drinking, and there is negative selection into moderate drinking. One interpretation of the negative selection into moderate drinking is that a "more sociable" person with an above average probability of being a moderate drinker socialises rather than works hard in the workplace, thus having a below average wage.
A wage decomposition to partition the wage gap between various drinking states is undertaken. The partition allows a focus on the pure productivity effect, which measures differences in the productivity of status $j$ versus status $k$ drinkers with the same observed characteristics. It is revealed that higher mean characteristics and higher returns to these characteristics contribute to the higher earnings of both light and moderate drinkers versus non-drinkers. Comparisons with research undertaken by Hamilton and Hamilton (1997) is possible in the case of the wage differential between moderate drinking and non-drinking. The results from the Australian twins data are consistent with those reported by Hamilton and Hamilton (1997). They show that moderate drinking leads to increased (pure) productivity in the workforce, and thus earnings. Hence, it is suggested that the substantial positive effect of moderate drinking on productivity, in the Australian twins sample, is hidden in the raw wage differential by negative sample selection into moderate drinking.

This paper, thus, indicates significant positive wage premiums for both light and moderate drinking in the Australian twins sample. 


\section{REFERENCES}

Ashenfelter, O. and A. Krueger (1994), "Estimates of the Economic Return to Schooling from a New Sample of Identical Twins", American Economic Review, Vol. 84(5), pp. 1157-1173.

Berger, M. C. and J. P. Leigh (1988), "The Effect of Alcohol Use on Wages", Applied Economics, Vol. 20(10), pp. 1343-1351.

Blinder, A. (1973), "Wage Discrimination: Reduced Form and Structural Estimates", Joumal of Human Resources, Vol. 8(4), pp. 436-455.

Dolton, P. J. and G. H. Makepeace (1987), "Interpreting Sample Selection Effects", Economic Letters, Vol. 24, pp. 373-379.

French, M. T. and G. A. Zarkin (1995), "Is Moderate Alcohol Use Related to Wages? Evidence from Four Worksites", Joumal of Health Economics, Vol. 14, pp. 319-344.

Halvorsen, R. and R. Palmquist (1980), "The Interpretation of Dummy Variables in Semilogarithmic Equations", American Economic Review, Vol. 70(3), June, pp. $474-475$.

Hamilton, V. and B. H. Hamilton (1997), "Alcohol and Earnings: Does Drinking Yield A Wage Premium?", Canadian Joumal of Economics, Vol. 30(1), pp. $135-151$.

Heckman, J. J. (1979), "Sample Selection Bias as a Specification Error", Econometrica, Vol. 47(1), pp. 153-161.

Heien, D. M. (1996), 'Do Drinkers Earn Less?", Southem Economic Joumal, Vol. 63(1), pp. 60-68.
Idson, T. L. and D. J. Feaster (1990), "A Selectivity Model of Employer-Size Wage Differentials", Joumal of Labor Economics, Vol. 8(1), pp. 99-122.

Kenkel, D. S. and D. C. Ribar (1994), "Alcohol Consumption and Young Adults Socioeconomic Status", Brookings Papers on Economic Activity: Microeconomics, pp. 119-161.

Lee, L. F. (1983), "Generalised Econometric Models with Selectivity", Econometrica, Vol. 51(2), pp. 507-512.

Miller, P. W., C. Mulvey and N. G. Martin (1995), "What Do Twins Studies Reveal About the Economic Retums to Education? A Comparison of the Australian and U.S. Findings", American Economic Review, Vol. 85(3), pp. 586-599.

Mullahy, J. and J. L. Sindelar (1993), "Alcoholism, Work, and Income", Joumal of Labor Economics, Vol. 11(3), pp. 494-520.

Oaxaca, R. (1973), "Male-Female Wage Differentials in Urban Labor Markets", International Economic Review, Vol. 14(3), pp. 693-709.

Veall, M. R. and K. F. Zimmermann (1996), "Pseudo- $R^{2}$ Measures for Some Common Limited Dependent Variable Models", Joumal of Economic Surveys, Vol. 10(3), pp. 241-259.

Zarkin, G. A., M. T. French, T. Mroz and J. W. Bray (1998), "Alcohol Use and Wages: New Results From the National Household Survey on Drug Abuse", Joumal of Health Economics, Vol. 17, pp. 53-68. 
Energy costs in the WA minerals industry

Daryal, M

Clements, K.W.

Daryal, $M$.

Clements, K.W. Johnson, P.L.

\section{Fels, A.}

Wu, Y.

$\mathrm{W} u, \mathrm{Y}$.

Siddique, M.A.B. Selvanathan, E.A.

\section{Groenewold, N}

Fraser, P.

\section{Ahammad $\mathrm{H}$.}

Islam, N.

Crompton, P.

Qiang, $Y$.

Qiang, Y.

Qiang, $Y$.

Qiang, X.

Qiang, Y.

Qiang, Y. Wage effects of drinking and smoking: an analysis using Australian twins
data

Prices, legislation and marijuana consumption

The economics of marijuana consumption

Minerals and regional employment in Western Australia

Western Australian agriculture: structure, trends and farming systems

A history of bimetallism: Greece, Rome, Middle Ages, Modern Times

The Trade Practices Act after 25 years: mergers and the role of the ACC

Income disparity and convergence in China's regional economies

Regional integration, productivity and growth: a study of the Southern China region

Export performance and economic growth: co-integration and causality analysis for Malaysia, 1966-96

Violation of the IID-Normal assumption: Effects on tests of assett-pricing models using Australian data

Estimating the WA agricultural production system: A profit function approach

Future trends in Japanese steel consumption

How different is mining from mineral processing?

The economy-wide effects of expansion of the minerals secto

The numerical implementation of WAM

An economy-wide model of Westem Australia: the theoretical structure

The nature of the Western Australian economy

CGE modelling and Australian economics
Lee, Y.L.

$98-29$

98-28

98-27
Magnani, L.

Le, A.T.

Greig, $\mathrm{R}$

Gruen, D. Kortian, $\mathrm{T}$

\section{ements, K.W.}

Chen, D.

Siddique, M.A.B.

Groenewold, N.

Hagger, A.

Macfarlane, L.J.

Ahammad, $\mathrm{H}$.

Greig, $R$.

\section{Groenewold, $\mathrm{N}$}

Fraser, P.

Yuen, W.C.

Wu, Y.

Le, A.T.

Clëments, K.W. Qiang, Y.

Clements, K.W Qiang, $\mathrm{Y}$.

Ghosh, R.N. Siddique, M.A.B.

Ahammad, $\mathrm{H}$.
Optimal schooling investments and earnings: an analysis using Australian twin data

Market volatility, adjustment of labor and eamings

Self employment and eamings among immigrants in Australia

The importance of the University of Western Australia to the state of Westem Australia: a preliminary assessment

Why does the Australian dollar move so closely with the terms of trade?

Simulating Demand Systems

Export performance and economic development in Thailand

The Australian natural rate of unemployment: some estimates from structural VAR

Shann Memorial Lecture:

Australian monetary policy in the last quarter of the twentieth century tariffs

Tests of asset-pricing models: how important is the IID-normal assumptions?

Food Consumption in rich countries

Redundancy and firm characteristics in Chinese state-owned enterprises The determinants of immigrant self-employment in Australia

A new input-output table for western Australia - Part 2

A new input-output table for western Australia - Part 1 .

The labour market in the Maldives: the case for institutional reforms

The economics of the WA minerals sector : an overview of ERC research 
Shifting matrices and their application to time series models in econometrics

Greig, R.

The Western Australian gold study

Part I

The performance of foreign direct investment in China: a preliminary analysis

Forecasting steel demand in South-East Asia

Clements, $K$.

An econometric study of gold production and prices

Report of the $1997 \mathrm{PhD}$ Conference in economics \& business

Ong, $\mathrm{L}$. Clements, $K$.

Izan, $\mathrm{H}$.

An analysis of the implications for the gold mining industry of alternative

Metal markets and East Asia: emerging trends, issues and policies Part III

Metal markets and East Asia: emerging trends, issues and policies Part II

Metal markets and East Asia: emerging trends, issues and policies Part I

The world real interest rate: stochastic index number perspectives

An andist of the implications for the gold mining industy

The natural unemployment rate in Australia since the seventies

The determinants of foreign direct investment in Australia 